\title{
Overseas Transmission of Hainan Opera
}

\author{
Shimin Yang ${ }^{1}$, Linyu Zhang ${ }^{2 *}$
}

\author{
${ }^{1}$ Hainan University \\ ${ }^{2}$ Hainan University \\ *Corresponding author. Linyu Zhang, Email: 419559905@qq.com
}

\begin{abstract}
Hainan Opera is one type of traditional Chinese Opera in Hainan Island, and the performers play in Hainanese dialect. Although Hainan Opera has a long history of overseas transmission, it attracts limited audience in foreign countries and regions. This paper aims to examine the existing problems of overseas transmission of Hainan Opera under the perspective of Lasswell's " $5 \mathrm{~W}$ " model of communication, and then learn the successful experiences of Peking Opera in spreading abroad, and finally propose suggestions.
\end{abstract}

Keywords: Hainan Opera, $5 \mathrm{~W}$ model of communication, overseas transmission.

\section{INTRODUCTION}

Hainan opera, also called Qiong Ju, is a type of Chinese opera in local Hainan province. Because the actors and actresses play the opera in Hainanese dialect, this stylized stage version was presented for an inevitably narrow audience [5]. As a typical art form that accenting the story's Hainanese setting and its regional roots, Hainan Opera has about two hundred years history of overseas transmission. The first Hainan Opera troupe went to Vietnam to perform in 1835 , in Daoguang Period of Qing Dynasty [14].

As the authorized government has announced the 2018 General Plan to establish China (Hainan) Free Trade Port, it is the right time to protect the traditional Hainan culture and strengthen the soft power of Hainan Province, especially by introducing Hainan Opera to foreign audiences. As more overseas spectators can appreciate the beauty of Hainan Opera, more attentions will be attracted in Hainan FTP.

In this essay, I will firstly follow Lasswell's " $5 \mathrm{~W}$ " model of communication in examining the current overseas transmission of Hainan Opera, and then learn some experiences of Peking opera, Sichuan Opera, and Yu Opera in Henan Province, and finally propose suggestions of developing Hainan Opera in the future.

\section{LASSWELL'S MODEL OF COMMUNICATION}

Harold Lasswell's model of communication describes an act of communication by defining who said it, what was said, in what channel it was said, to whom it was said, and with what effect it was said [6]. This research norm is well known for his " $5 \mathrm{~W}$ " model of communication, which focuses on "Who (says) What (to) Whom (in) Which Channel (with) What Effect". There are five parts in the model, including communicator, information, media, audience and effect. Such five research fields provide a very good point of view to study the overseas transmission of Hainan Opera. Former studies have applied this theory in analyzing other types of Chinese operas, such as Zhuang drama and Buyi people's dixi drama [1]. However, few similar researches have taken in Hainan Opera from the perspective of cross-cultural communication.

\section{PROBLEMS}

Although Hainan Opera has successfully spread to some countries and regions in the world, such as Singapore, Malaysia, Thailand, and America, its fame overseas is still quite faint. There are some problems in its audience, communicator, information, media, and effect, which calls for improvement in the future development.

First, the audience is limited to overseas Chinese spectators. Several troupes of Hainan Opera were invited to perform in the important festivals in foreign countries and regions. For example, Li and Wu's Hainan Opera troupe performed in Malaysia (1938), Guangdong Provincial troupe was invited to perform Hainan Opera in Thailand and Singapore (1982), Hainan Provincial 
troupe performed in Malaysia and Singapore (1992, 1994), and the troupe of Arts and Culture School of Hainan Province was invited to perform Hainan Opera in Singapore (2018). Except the case of Hainan Provincial troupe performed in Paris (2018), there are still not many non - Chinese audiences watching Hainan Opera in recent years.

Second, communicators refer to the actors and actresses in Hainan Opera troupes. Arts and Culture School of Hainan Province is the only professional institution that has the major of Hainan Opera. Not many actors and actresses in Hainan Opera troupes, especially the old performers, has the opportunity to receive higher education in colleges [8]. Talents such as scriptwriters and directors are in need in developing local Chinese Opera, and good translators who are able to help the overseas audience overcome the language difficulties are also needed in overseas transmission [9].

Third, information refers to the plays of Hainan Opera. Traditional plays, like Official Hai Rui, and $A$ Good Match Met by Chance (Hong Ye Ti Shi), are warmly welcomed by old Hainan audience, as well as overseas spectators of Hainan Opera [11]. Modern plays, like Go to the Southeast Asia (Xia Nanyang), remind the audience the history of Hainan Island, and also unite Hainan people to strive for brighter future together [7]. However, there are not many modern plays describing the present development of Hainan Province in the $21^{\text {st }}$ century, and few of these modern plays were performed for the overseas audience [12].

Fourth, media. The present media, or transmission form, is to invite local Hainan Opera troupes to perform in foreign countries or regions with Hainan people, like Singapore, Malaysia, and Thailand. New media forms, like live video streaming, did not play its role in broadcasting Hainan Opera to the world. However, other form of Chinese Opera, such as Sichuan Opera, did explore fresh ways of spreading their performances to a larger audience, both in and out of China. For instance, Resist as a Lying Tiger (Wo Hu Ling), a famous play in Sichuan Opera, was performed online through live video streaming in 2013 and gained audience all around the world, which was the first successful example of spreading Chinese Opera in this way [4].

Fifth, effect of communication remained plain at present. As an important art form in Hainan Island, Hainan Opera has the responsibility to spread the rightness and kindness to the audience [2]. However, the present overseas transmission did not achieve expected communication effect, such as to broadcast the present Hainan Island as Free Trade Port, etc. One reason for this deficient effect lies on its limited overseas audience, and nearly few non - Chinese audience has been attracted to watch Hainan Opera in theatres or festival activities. Another reason would be the lack of newly written plays about the development of Hainan today
[13].

\section{FINDINGS}

This study has investigated the overseas transmission experiences of Peking Opera, Yu Opera in Henan Province, and Sichuan Opera, therefore the author summarized two valuable lessons to learn in further developing Hainan Opera.

\subsection{New Communicators}

Zhang Huoding, the famous Peking Opera singer, performed The Lucky Purse (Suo Lin Nang), and the Legend of the White Snake (Bai She Zhuan) at the David H. Koch Theater at Lincoln Center, New York City, in her US debut in 2015. Zheng emphasized the efforts of the cooperation with National Academy of Chinese Theatre Arts [16]. In order to organize the activity, Zhang Yao, the dean of the academy, worked as the Chief Artistic Officer. What's more, there was a group with 50 teachers and 30 students from the academy, and this group went to America to offer professional help for this performance. The English department from the college of International Cultural Exchange was in charge of the translation. It is right to conclude that the cooperation with universities determines the success for some degree, and it is time for Hainan Opera to seek opportunities to work with local educational institutions.

Additionally, the Art Troupe of Sichuan Opera in Chong Qin University was invited to perform in five Confucian Colleges in Spain, and the troupe also attended the local Pilar Musical Festival to communicate with other Spanish art performers. Local audiences were attracted by the beauty of Sichuan Opera, and news press broadcasted that the troupe's performance displayed the precious art of oriental opera in China.

\subsection{New Media}

Unlike former overseas performances, Zhang Huoding's debut did not follow the routine of free tickets policy. The charging company hired the experienced commercial group in America to propagandize the Peking Opera singer Zhang Huoding in advance, including the English website to introduce her, the meeting with Peking Opera fans, news report about Zhang's debut to New York, etc. After months of the hype, the tickets were sold out before the performance, and attracted plenty of American audiences, not only Chinese in America. The organizers admitted that the publicity campaign did play its essential role in the success [16].

What's more, Yu Opera in Henan Province established a comprehensive media platform, including online performance through live video streaming, 
mobile phone APP, VR live broadcast, and community radio ( $\mathrm{Li}, 2017)$. With these modern techniques, Yu Opera has attracted more and more young audiences.

\section{DISCUSSIONS}

Based on the above findings of the success of Peking Opera singer Zhang Huoding's debut to America, as well as the experiences of Sichuan Opera and Yu Opera, the author would propose three suggestions for the development of Hainan Opera in the paper.

First, it is suggested to cooperate with colleges and universities to cultivate more professional talents of Hainan Opera. Hainan University had once set a project of National Arts Foundation in 2018, which aims to help Hainan Opera performers with academic education. The author considers it as very good attempt, and Zhang also mentioned more similar projects are encouraged to offer performers opportunities to study in local universities and colleges [15].

Moreover, as the language would be a major difficulty faced by foreign audience in enjoying Hainan Opera, translators of plays and interpreters of performances can offer professional support in overseas transmission. Local educational institutes, such as English department of local universities, have the ability to handle the difficult task of opera translation which requires abundant knowledge of traditional culture and high-level translating skills.

Second, it is suggested to enrich the media with available resources. Instead of inviting Hainan Opera troupes to perform overseas, it is more convenient to invite foreign students in Hainan Province to experience its beauty. For example, the Qiongzhou Cup Contest of International students holds every two years in Hainan Province, and it is a good chance to spread Hainan Opera if the contesters are encouraged to perform Hainan Opera by themselves.

Another trail suggestion would be the annual Spectrum in Boao, and abstracts of Hainan Opera can be added in the tea-break time. In addition, Confucius Colleges which cooperated with Hainan University and Hainan Normal University, are encouraged to invite troupes of Hainan Opera to perform overseas.

Except for the traditional form of performance, modern techniques should play active role in promoting the development of future Hainan Opera. For example, Hainan Opera can apply the new forms of live video streaming, mobile phone APP, VR live broadcast, and so on.

It is necessary to mention that commercial performance form should be taken into consideration when troupes of Hainan Opera are invited to perform overseas. Free tickets policy is turning faint in attracting audiences and arousing local attention nowadays. Just like the debut of Zhang Huoding in America (2015), the performance achieved great success without free tickets, and local press showed huge interests in reporting this event.

Third, it is important for young generation in Hainan Province to enjoy and appreciate the beauty of Hainan Opera. Because only with young audiences, the Hainan Opera will exist and develop continually. There is a good instance in Qiongshan Middle School in Haikou City, which selected the course of Hainan Opera for students in their spare time. What's more, an amateur troupe of Hainan Opera has been organized in the school to perform sometimes. It is a good way to help young students to know the traditional culture of Hainan Island, and more schools are called for to participate in the project.

\section{CONCLUSION}

Hainan Opera is the living art of traditional culture in Hainan Province, and it is a natural connection with overseas Hainan people as well as a useful way to broadcast the present development. More attentions must be paid in its overseas transmission in the future.

Hainan government should announce proper policies to develop Hainan Opera troupes, like cultivating the professional levels of performers, creating high-quality plays, and organizing successful performances to attract the audience in the world.

Universities and colleges in Hainan Province can offer training programs for the actors of Hainan Opera, in order to improve their performance level. Foreign language services must be equipped with the overseas transmission of Hainan Opera, too. Translators and interpreters would be cultivated in helping to broadcast the beauty of Hainan Opera in the world. Projects of translating classical plays of Hainan Opera must be encouraged with financial sponsorship.

With the cooperation with local governments and educational institutions, Hainan Opera can have brighter future in overseas transmission in the new era of establishing Free Trade Port.

\section{AUTHOR'S CONTRIBUTION}

Linyu Zhang is the lecturer of English in Hainan University. She is a $\mathrm{PhD}$ candidate in translation and interpretation in Putra University of Malaysia. She is now leading a Research Project of Hainan Province, named Overseas Transmission of Hainan Opera in the Internet Era (Hnky2019-20).

Shimin Yang is the lecturer of English in Hainan University. She is also a member of the Research Project (Hnky2019-20). 


\section{ACKNOWLEDGMENT}

I would like to thank Hainan Provincial Research Project, Overseas Transmission of Hainan Opera in the Internet Era (Hnky2019-20) to provide the fund sponsor.

\section{REFERENCES}

[1] Chen, L.Q, Zhuang Drama and Folk Culture, Journal of Guangxi University for Nationalities (Philosophy of Social Science Edition), 33(02) (2011) 136-139.

[2] Chen. Y. F., Broadcasting and Developing Hainan Opera under the Circumstance of New Media. Home for Drama, (27) (2020) 35-51.

[3] Dong, Z. K., Research on the Segmentation of Art Market Based on Consumer Behavior---Take the Hainan Opera Market in Haikou as an Example, Hainan University, 2020,

[4] Gao, S. H., Modern Spread of Sichuan Opera in the International Era, Sichuan Drama, (05) (2017) 48-52.

[5] Harris, K., Re-makes/re-models: The Red Detachment of Women between stage and screen. The Opera Quarterly, (26) (2010) 316-342.

[6] Lasswell, H., Bryson, L., (Ed.) The Structure and Function of Communication in Society. The Communication of Ideas. New York: Institute for Religious and Social Studies, (1948).

[7] Li, J.Y., Improving the art of Hainan Opera---Take an Example of Hainan Opera Play "Go to the Southeast Asia", Music Zoom, (13) (2014) 47-48.

[8] Research Group of CAPD (China Association of Promoting Democracy), Development of Hainan Opera in Establish International Tourism Island, in: (Eds.), National Strategy of Establishing Hainan into the International Tourism Island---Proceedings of the $60^{\text {th }}$ Anniversary of PRC in Hainan Province, 2009, pp. 188-194.

[9] Wang, H. Y., Language Obstacles in Overseas Transmission of Henan Opera. News Research, (04) (2018) 30-33.

[10] Xiao, K, Acknowledge, Introduce, and Innovate---The Heritage and Development of Buyi People's Dixi Drama, Guizhou Minzu University, 2012.

[11] Xue, R.L., Impressive and Special Image of Good Officer---Hainan Opera Play "Officer Hai Rui", Chinese Drama, (01) (2014) 13-14+12.

[12] Ye, Y, Development of Hainan Opera will Prompt the Prosperity and Advancement of Hainanese Social Life and Traditional Culture, Hainan Today, (08) (2012) 42.

[13] Yu, W. X., The Value of Hainan Opera as the Intangible Cultural Heritage and its Protection. Home for Drama, (17) (2021) 36-37.

[14] Zhang, M. H., Spreading Hainan Opera in China and Southeast Asia. Drama and Literature, (8) (2014) 111-115.

[15] Zhang, C. Y., Heritage and Development of Hainan Opera. Heritage, (06) (2021) 54-55.

[16] Zheng, L. Y., Zhang Huoding's Debut in America and the Overseas Transmission of Peking Opera. Music Communication, (02) (2017) 77-81. 